\title{
QUANDO EU ENTREI NA ESCOLA... MEMÓRIAS DE PASSAGENS ESCOLARES
}

\author{
Mônica de Carvalho Magalhāes Kassar ${ }^{*}$
}

RESUMO: Na educação de pessoas consideradas mentalmente incapazes, relatos escolares geralmente são construídos a partir do olhar dos professores ou da análise de documentos. Ao tentar abordar diferentes aspectos do processo educativo, este artigo propóe-se a conhecer e analisar a escolaridade através da memória de adultos que, quando crianças, foram considerados "deficientes mentais" e, portanto, passaram por experiências educacionais diferenciadas. O material para análise foi recolhido de uma pesquisa em que foram localizados e entrevistados ex-alunos de classes especiais para deficientes mentais. Partindo do pressuposto de que a memória é socialmente construída e os discursos formam-se nas relações sociais, os depoimentos são analisados num contraponto aos documentos escolares e aos depoimentos de professores dessas classes especiais. Os depoimentos dos adultos (ex-alunos) e dos professores foram tomados em diferentes tempos: os de ex-alunos foram recolhidos recentemente e tratam de suas memórias escolares e os de professores foram registrados há cerca de quinze anos e referem-se às imagens daquelas crianças, os adultos de hoje.

Palavras-chave: Memória. Escola. Deficiência mental.

\section{When I ENTERED SCHOOL... MEMORIES OF SCHOOL PASSAGES}

ABSTRACT: School accounts on people considered mentally disabled are usually based on the teachers' views or on document analyses. In its approach to different aspects of the educational process, this paper strives to know and analyze schooling through the memory of adults who were considered as 'mentally disabled' when children and thus underwent different educational experiences. The analysis material was collected in a research that traced and interviewed ex-pupils from

* Doutora em Educação e professora da Universidade Federal de Mato Grosso do Sul (UFMS), Campus de Corumbá.E-mail: mkassar@terra.com.br 
special classes for the mentally disabled. Assuming that memory is socially built and speeches form within social relationships, their statements are analyzed in contrast to the school documents and the interviews with those special class teachers. The adults (ex-pupils) and teachers' statements were collected in two different moments: the expupils' school memories are recent, whereas those of the teachers date from approximately fifteen years ago and refer to the images of those children, who are now adults.

Key words: Memory. School. Mental disability

\section{Introdução}

A

história das pessoas consideradas deficientes, de modo geral, tem sido contada através do conhecimento e análise de documentos institucionais, legislação ou outras formas de registros escritos (citamos como exemplo Pessotti, 1984; Bueno, 1991; Michelet \& Woodill, 1993; Mazzota, 1996; Jannuzzi, 2004a; entre outros). Esses trabalhos têm oferecido muitos elementos para que seja possível conhecer a educação dessas pessoas. Não desconsiderando essas contribuiçôes, este trabalho propõe-se a abordar aspectos do processo educativo, ouvindo meandros da história da educação especial, pela memória de adultos que, quando crianças, foram considerados "deficientes mentais" e, portanto, passaram por experiências educacionais diferentes das proporcionadas a grande parte da população. Essas pessoas, durante o processo escolar, foram vistas socialmente como comprometidas pela deficiência mental.

Estudos já publicados (Omote, 1980; Schneider, 1985; Glat, 1989) demonstraram que, quando as crianças recebem o diagnóstico de "deficiente", de certa forma, inicia-se à sua volta um "tratamento especial" repleto de condiçôes socialmente restritivas, que acabam por imprimir marcas na relação entre o outro e ela. Essa população passa a ser vista como mentalmente incapaz, portanto, socialmente desacreditada e estigmatizada. Goffman, ao estudar situações de estigma, nos adverte que: "Por definição, é claro, acreditamos que alguém com um estigma não seja completamente humano. Com base nisso, fazemos vários tipos de discriminações, através das quais efetivamente, e muitas vezes sem pensar, reduzimos suas chances de vida" (Goffman, 1980, p. 15).

Cad. Cedes, Campinas, vol. 26, n. 68, p. 60-73, jan./abr. 2006

Disponível em <http://www.cedes.unicamp.br> 
Quando eu entrei na escola... memórias de passagens escolares

Bueno (1997) nos fornece elementos para a compreensão da relação entre a sociedade e a pessoa mentalmente desacreditada, ao analisar as instituiçôes de caráter filantrópico especializadas em atendimento às pessoas com deficiências. $\mathrm{O}$ autor acredita que, pela ineficiência de seus atendimentos, tais instituiçôes acabam reforçando a idéia socialmente difundida da incapacidade dessas pessoas.

O descrédito em relação a essas pessoas, em especial em relação à sua escolaridade, é bastante presente também na literatura especializada, que confirma crenças socialmente difundidas. Sica ((1991, p. 110) é exemplar dessa posição quando afirma que os "deficientes mentais educáveis" são potencialmente capazes de "um aprendizado mínimo das tarefas escolares". Diante de toda essa história de descrença, ouvir as memórias dessa população em relação à sua escolaridade transforma-se em um caminho instigante.

\section{O discurso, a memória e a constituição de sujeitos na história}

Para o desenvolvimento deste trabalho é necessário esclarecer os ancoradouros que serviram de base para a fundamentação de nossas análises. Partimos do princípio de que a memória das pessoas é um processo que se constitui mediado na dinâmica das relações em que estão imersos os sujeitos. Ao retomar a lei geral de desenvolvimento proposta por Vygotsky (1981), entendemos que, para que as características especificamente humanas (funções psíquicas complexas) apareçam e se desenvolvam no sujeito, é necessário o contato com o outro, pois "é através dos outros que nós nos desenvolvemos" (Vygotsky apud Smolka, Góes \& Pino, 1995, p. 179-180). A memória é concebida, portanto, como uma função psíquica complexa do ser humano.

Os trabalhos de Vygotsky e Bakhtin, no curso do pensamento desenvolvido por Marx e Engels, apontam para o fato de que o desenvolvimento do psiquismo se dá dentro das possibilidades oferecidas, em última instância, pelas condiçōes sócio-culturais. Essas condiçōes possibilitam a constituição do que se pode chamar de "especificamente humano". Partindo desses pressupostos, entende-se que a sociedade não é um mero "contexto" no qual o homem se desenvolve. A sociedade é constitutiva do homem, as "condições sociais (...) estão na origem da sua consciência, elas a criam" (Schaff, s/d, p. 78). O homem traz em sua 
individualidade aspectos da própria sociedade. $\mathrm{Na}$ base dessas afirmações, identificamos pensamentos expressos por Marx, quando afirmou que "não é a consciência dos homens que determina seu ser; é o seu ser social que, inversamente, determina sua consciência" (Marx, 1983, p. 24).

Como se dá a relação entre homem e sociedade? Como a sociedade se faz presente na constituição do sujeito e de sua memória? Trabalhos como os de Vygotsky, Luria e Bakhtin elucidam essa relação ao ressaltarem a importância da criação e utilização dos signos e, entre eles (e principalmente), da linguagem na constituição da especificidade humana. A linguagem é concebida como fundamental para o surgimento e o desenvolvimento do pensamento característico humano. Para Vygotsky, "o pensamento não é simplesmente expresso em palavras; é por meio delas que ele passa a existir" (Vygotsky, 1987, p. 108). Os signos têm um caráter constitutivo para o homem, possibilitando a interação social, a atribuição/apreensão/generalização de significações (Smolka, 1997). Nesse processo, "a experiência verbal individual do homem toma forma e evolui sob o efeito da interação contínua e permanente com os enunciados individuais do outro", num processo de "assimilação, mais ou menos criativo das palavras do outro" (Bakhtin, 1992, p. 313-314). Portanto, as palavras que constituem o pensamento e a memória dos sujeitos são apropriadas nas relações sociais, nas relaçôes do sujeito e o outro.

Bakhtin (1988, p. 48) argumenta que a própria consciência humana constitui um fato sócio-ideológico, ao admitir que o pensamento individual é constituído nas práticas sociais, na/pela linguagem, na apropriação do pensamento socialmente produzido. Braga (2000) relaciona o estudo da consciência ao estudo da memória, afirmando que "o estudo da memória está (...) inserido numa questão maior compartilhada pelos autores da perspectiva histórico-cultural: a gênese da consciência" (Braga, 2000, p. 86). A relação entre a consciência e a memória é perpassada pela existência da linguagem como elemento constituinte do pensamento humano. Luria (1979) explica que o aparecimento da linguagem implica fatores determinantes para o desenvolvimento da consciência e da própria memória, pois, ao designar um objeto por um nome, cria-se a possibilidade de discriminá-lo e conservá-lo na memória, independente de sua presença futura. As palavras abstraem propriedades dos objetos que nomei$\mathrm{am}$, relacionando-os e formulando categorias. Esta possibilidade "assegura a transição do sensorial ao racional na representação do mundo" (Luria, 1979 , p. 80). Luria argumenta, ainda, que "a linguagem do homem the 
Quando eu entrei na escola... memórias de passagens escolares

permite desligar-se pela primeira vez da experiência imediata e assegura o surgimento da imaginação" (idem, ibid., p. 83).

Concebemos, portanto, o discurso e a memória do sujeito intimamente ligados à sociedade na qual se encontram imersos. No movimento social, os discursos se antagonizam, se completam, se ignoram, se fundamentam mutuamente... Sob esse olhar, dizemos, os sujeitos quando se recordam e falam de suas memórias refletem e refratam as relações socialmente e historicamente produzidas. Relaçóes essas apropriadas nas práticas sociais, entre os homens, permeadas no/pelo discurso, de modo que "nosso próprio pensamento nasce e forma-se em interação e em luta com o pensamento alheio" (Bakhtin, 1992, p. 317).

O discurso e a própria memória estão circunscritos pelas possibilidades materiais e ideológicas que os produziram. No relato das memórias, os discursos entrelaçam-se à história: à história das próprias pessoas e à história social. Cada "produto" histórico, e aí podemos identificar o discurso e a própria memória contada, está repleto de significados, constituídos na história social. Braga (2000) identifica em Halbwachs (1990) também uma forte relação entre indivíduo e sociedade a respeito da constituição da memória. O autor, que parte de outros fundamentos, ${ }^{1}$ afirma que o ato individual de lembrar está enraizado nas instituições sociais (classe social, família, profissão etc.). Ressaltando os estudos de Halbwachs, a autora diz que a "memória autobiográfica insere-se na memória histórica” (Braga, 2000, p. 86).

As memórias trazem enunciados em que vozes se entrecruzam numa relação polifônica, pois a palavra implica multiplicidade de vozes. $\mathrm{Na}$ apropriação de pensamentos e de práticas sociais, as vozes dos outros passam a povoar a atividade mental individual. Nos discursos, os sentidos se encontram, são retomados, reiterados, negados, numa relação polissêmica. Braga (2000), recordando-se de Bartlett (1977), retoma o adágio popular "quem conta um conto, aumenta um ponto" e acrescenta: "não só aumenta; às vezes omite, modifica, simplifica, inventa. Quem recorda, conta uma outra história" (Braga, 2000, p. 85). Quais as histórias a serem contadas (lembradas) por hoje-adultos, ontem-crianças "desacreditadas"?

Para o desenvolvimento deste texto, escolhemos a memória de um sujeito, ex-aluno de classe especial, que aqui recebe o nome de Ana. ${ }^{2}$ Suas memórias foram colhidas recentemente, em 2000, quando contou suas ex- 
periências educacionais ocorridas entre 1982 e 1992 . Ana, no momento da realização da entrevista, tinha 23 anos, era casada e tinha dois filhos.

Há que se acrescentar que possuíamos depoimentos de professores de classes especiais sobre "alunos de classes especiais", colhidos há aproximadamente 15 anos, ou seja, no período em que Ana freqüentou essas salas. $^{3}$

\section{Breve história oficial de Ana ${ }^{4}$ e a educação especial entre 1980 e 1990}

O início da vida escolar de Ana foi em 1982, aos 7 anos, na $1^{\text {a }}$ série. Ficou nessa série até 1985 (dos 7 aos 10 anos). Em 1986 (com 11 anos, após 4 anos freqüentando a $1^{\text {a }}$ série) foi transferida para a classe especial, aí permanecendo até a data de uma avaliação psicopedagógica realizada em 1989 (após 4 anos de freqüência na classe especial, então com 14 anos). Após essa avaliação, Ana foi reencaminhada para classe do ensino regular.

O período em que Ana freqüentou a escola é anterior à promulgação da atual Lei de Diretrizes e Bases da Educação Nacional (LDB/96) e à disseminação do discurso sobre inclusão educacional. $\mathrm{Na}$ época, o discurso corrente na educação especial era o da integração, apoiado no conceito de normalização. Normalizar significava oferecer aos excepcionais ${ }^{5}$ condiçóes de vida próximas às que outras pessoas recebem, ensinando-os a levar uma vida tão normal quanto possível (Jannuzzi, 2004b). Uma das práticas comuns apoiadas nesse discurso foi o encaminhamento de centenas de crianças que freqüentavam classes especiais para salas de aula do ensino comum em todo o país e também no município onde Ana estudou. ${ }^{6}$

As classes especiais para deficientes mentais foram implantadas na região em 1977, quando as crianças começaram a ser encaminhadas para esse atendimento por decisão interna da escola, considerando-se anos de repetência ou por dificuldades acadêmicas identificadas pelo professor, de forma coerente com o estabelecido pela Legislação Educacional Federal (4.024/61 e 5692/71), vigente na época. A partir do ano de 1988, a Secretaria de Educação do estado de Mato Grosso do Sul iniciou um processo de avaliação diagnóstica para identificação dos possíveis casos de deficiência mental. Inicialmente, todos os alunos que já freqüentavam as classes especiais passaram por esse processo. Posteriormente, foram avali- 
Quando eu entrei na escola... memórias de passagens escolares

adas as crianças que eram indicadas para o ingresso nessas classes. Com a implementação do diagnóstico, a partir de fins de 1988, houve um significativo decréscimo de matrículas nas classes especiais para deficientes mentais em todo o estado. Essa mudança também foi registrada no município pesquisado. ${ }^{7}$ Ana, que já freqüentava classe especial, passou por esse processo.

\section{Relatos de Ana: memória e história}

Quando eu entrei na escola, eu entrei com sete anos, eu não fui pro prezinho... já fui pra primeira série... Aí eu tinha dificuldade para entender... estudava e chegava lá, esquecia e a professora: 'estuda, estuda, tem que aprender'... Até que foi um dia, chamou minha mãe pra ir lá na escola, pra comunicar que eu tinha dificuldade de aprender... Aí surgiu pra mim (sic) entrar nessa sala especial. Foi bom pra mim porque os professores faziam todos os tipos de trabalho. A professora liberava eu pra ir pra sala especial, ai eu comecei a me esforçar em casa... Meus pais me ajudavam, meu irmão... E a maior dificuldade minha era de aprender a ler. Eu tinha maior dificuldade mesmo é de aprender a ler... Soletrar então! A professora pegava no meu pé... Foi super legal, que os professores ajudavam... Tudo era em grupo, em quatro professoras que puxavam a gente. Tinha uma que fazia brincadeira, trabalho, quebra-cabeça, sabe? As coisas, se eu tinha algum problema, "Ana, se você se esforçar, você vai ser uma boa aluna”. Tinha que estudar bem (...).

Aí eu peguei e continuei lá na escola, só que teve uma época que mamãe foi lá, via meus trabalhos, fazia trabalho, tinha reunião lá pra ela, ela tinha que participar também da sala especial com as professoras... Faziam perguntas como que era em casa... se meu pai me maltratava, se meu pai me batia, se meus irmãos batiam em mim... pra mim ter essa dificuldade que eu tinha na escola!

Só que eu falava pra professora que não tinha problema em casa, familiar, porque ninguém nunca me bateu, nem minha mãe, nem meu irmão pra 'mim' aprender...

“- Mas, você nunca apanhou?” Eu falei: não! Nunca minha mãe bateu em mim... Eu sou a caçula deles e eles nunca me bateram. Eles pensavam que meu pai me batia pra 'mim' ter esse problema. Aí, só que eu falei assim que eu também já entrei tarde na escola, pensei que ia entrar com seis e entrei com sete...

Ana vai se recordando de sua passagem entre a classe comum e a classe especial. Na recordação há a dificuldade de aprender: “... Aí eu tinha dificuldade para entender... estudava e chegava lá, esquecia”. Há, 
também, a insistência da professora: "estuda, estuda, tem que aprender" ou o incentivo: "Ana, se você se esforçar, você vai ser uma boa aluna". Ana se recorda que, devido a essa dificuldade, foi encaminhada para uma classe especial e lá ficou por quatro anos. Essa também é a causa apontada pelo discurso do professor relembrado pela memória de Ana: "Até que foi um dia, chamou minha mãe pra ir lá na escola, pra comunicar que eu tinha dificuldade de aprender... Aí surgiu pra mim (sic) entrar nessa sala especial."

Reconstruindo a história de Ana, por meio da busca de informações em sua avaliação psicodiagnóstica, datada de 1989, ou seja, realizada após quatro anos de frequêencia na classe especial, vimos que a aluna durante a avaliação respondeu adequadamente às questōes solicitadas, demonstrou-se "interessada e muito observadora, respondendo com convicção e clareza a todas as perguntas apresentadas". Ainda, segundo o relatório arquivado no setor de Educação Especial, Ana escrevia o que falava, lia o que escrevia e demonstrava habilidade em usar conceitos e operaçōes numéricas. Como resultado da avaliação, Ana deveria ser encaminhada, no próximo ano, para o ensino regular, o que realmente aconteceu, segundo seu relato: "Depois que eu sai dessa sala especial, eu fui pra $1^{a}$ série, mesmo, normal. Aí as professoras me deram a maior força 'Ah! Até que um dia você passou...' e só você passou da sala especial!".

Nos documentos educacionais há o registro de que, após uma avaliação psicoeducacional, Ana foi reinserida em uma classe comum. Nas memórias de Ana, há a certeza de que, após anos de esforço e dedicação dela, de seus professores e de sua família, ela "passou pra uma 1a série, mesmo, normal”. Na história oficial há um processo de diagnóstico. $\mathrm{Na}$ memória de Ana não há registros de avaliaçōes, só do esforço. Retomando nossos pressupostos, afirmamos que o sujeito traz em sua individualidade aspectos da própria sociedade; Ana traz aspectos de sua vida na escola, através da voz das professoras: "estuda, estuda, tem que aprender" ou "Ana, se você se esforçar, você vai ser uma boa aluna".

Quais os motivos que teriam levado Ana a ser encaminhada para uma classe especial? Segundo o relatório sobre sua vida escolar, Ana foi encaminhada a uma classe especial por apresentar "distúrbios de atenção". Retomamos a história da educação especial no município estudado e ressaltamos que, até a data de 1988 , as crianças eram encaminhadas às classes especiais por decisão interna da escola. Ao retomar depoimentos 
Quando eu entrei na escola... memórias de passagens escolares

de professores que atuavam em classes especiais naquele momento, buscamos algumas pistas para entender esse processo:

A gente conversava com o professor da $1^{\text {a }}$ série: "- Se tiver aluno, assim, que não esteja acompanhando a turma...” e aí eles mandavam pra gente. Por exemplo, número de repetências, dois anos na $1^{\text {a }}$ série já era clientela de classe especial. (Professora Regina, 17 anos de magistério, relatando os encaminhamentos para classes especiais antes da utilização de avaliações diagnósticas. Depoimento colhido em 1990)

Bakhtin (1988, p. 48) argumenta que o pensamento individual é constituído nas práticas sociais, na apropriação do pensamento socialmente produzido. Ao ouvir a professora, de certa forma, ouvimos também o disposto na Lei Educacional 5.692/71, vigente à época, que previa tratamento especial a alunos "em atraso considerável quanto à idade regular de matrícula" (Art. $9^{\circ}$ ). O encaminhamento de Ana para uma classe especial parece, portanto, estar relacionado ao seu insucesso escolar e às conseqüentes reprovações.

Qual o olhar da literatura a respeito do fracasso? Ferreira (1986), a partir do estudo elaborado sobre manuais de psicologia adotados nos cursos de pedagogia, mostra-nos algumas caracterizaçôes encontradas a respeito das crianças de classes populares. Segundo os manuais estudados, essas crianças são as "crianças que fracassam" e a elas são relacionados atributos como "indisciplinadas, desnutridas, carentes afetiva e culturalmente, deficientes intelectualmente" (Ferreira, 1986, p. 8).

Que idéias perpassam as mentes das professoras em relação às possíveis causas do fracasso ou, no caso de crianças encaminhadas para classes especiais, da própria deficiência mental? Nas falas de nossas professoras encontramos a apropriação desses discursos socialmente difundidos:

(...) a deficiência mental, a dificuldade de aprender, eu acho que vem daí, porque a criança não é bem alimentada, não tem saúde, não dorme direito, é... a maioria vive, assim na rua, vendendo as coisas, ajudando os pais, ou então já vive na rua porque não tem nem pai nem mãe em casa, né? (Professora Olinda, dez anos de magistério. Depoimento colhido em 1990)

Contini (1988), em trabalho realizado no mesmo município com professores alfabetizadores, na década de 1980, mostra-nos a identificação desses mesmos atributos nas falas desses professores quanto à relação 
insucesso escolar/condição (falta de) de seus alunos. $\mathrm{O}$ fracasso escolar parece ser sempre atribuído não só às características apresentadas pelas crianças, mas também a uma família que supostamente não se envolve com seu filho e não propicia, portanto, o desenvolvimento das habilidades intelectuais. O depoimento da professora Olinda reforça essa posição, quando dizia acreditar que as crianças de classe especial "não têm estímulo em casa, [eram de] famílias muito pobres, que não ajudavam em nada”. Regina, que em 1990 já atuava como professora há 17 anos, afirma: "Pra mim, a deficiência mental acho que é assim... são pessoas muito carentes mesmo... Carente de tudo, de afeto, de alimentação... bem pobre mesmo". Mais adiante, enfatiza: "Que a gente vê que são crianças de pais que, assim, bem, que bebe, que briga, que se droga, entendeu?".

Mas, na memória de Ana, sua família foi participante de seu sucesso: "Meus pais me ajudavam, meu irmão...". E Ana? O que diz de seu fracasso? De seu depoimento, escolhemos as observações que faz em relação às suposições apresentadas a respeito de seu insucesso na escola. Ela diz que deveria ter entrado com seis anos na escola, como provavelmente outros colegas. Sua dificuldade foi, por ela, atribuída ao fato de não ter cursado uma pré-escola: "eu também já entrei tarde na escola, pensei que ia entrar com seis e entrei com sete". A importância atribuída à pré-escola por Ana foi também atribuída pela professora Olinda, em 1990. Segundo ela, o aluno de classe especial seria aquele "aluno que nunca foi trabalhado, que nunca teve o pré, né?".

Ana, hoje adulta, argumenta com seus professores em sua memória: "Aí, só que eu falei assim que eu também já entrei tarde na escola, pensei que ia entrar com seis e entrei com sete...". Ana teria falado com seus professores quando criança ou fala hoje sobre suas suposiçōes ao recordar aquele processo? $\mathrm{Na}$ constituição de sua memória, os argumentos parecem se misturar entre as diferentes vozes que povoam seus pensamentos. O discurso de Ana, num processo de "assimilação, mais ou menos criativa, das palavras do outro" (Bakhtin, 1992, p. 313-314), também deixa claro que há outras suposiçôes por parte da equipe que a atendeu (talvez a do diagnóstico?) em relação aos motivos de seu fracasso: "Eles pensavam que meu pai me batia pra 'mim' ter esse problema". E evoca a voz da professora: "Mas, você nunca apanhou?". A suposição de uma "desestruturação familiar" parece sair dos manuais de psicologia e ecoar da voz das professoras: "a gente sente que ela (criança) tem mais necessidade afetiva do que econômica... a gente sente que tem problema 
Quando eu entrei na escola... memórias de passagens escolares

na família, que são filhos de pais separados" (Rosa, com 5 anos de magistério). E como num outro adágio popular, "uma mentira que de tanto contar vira verdade", essa suposição parece transformar-se em uma certeza: "a gente vê que são crianças de pais que, assim, bem, que bebe, que briga, que se droga" (Regina).

\section{Ainda algumas considerações}

O processo educacional das pessoas é constituído de histórias, histórias registradas por documentos, histórias reconstruídas por memórias. Documentos e memórias individuais completam-se na busca de pistas para entender as muitas histórias da História.

A polissemia presente nos documentos (leis e literatura) que nos falam dos limites a respeito da deficiência está presente no discurso dos sujeitos que vivem a história, que vivem o registrado pelo material documental, legal e acadêmico. Ana, ao trazer a sua história, sem saber, traz também a história de outras Anas, Joãos, Marias, Pedros... Traz também parte das histórias de seus professores e outros aspectos ignorados nos projetos educacionais propostos e implantados em um determinado tempo e lugar.

A memória de Ana, que foi um dia desacreditada, toma voz e conta aspectos da história da educação especial. A luta e as contradiçóes entre as imagens que os professores tinham a respeito das "crianças de classe especial" e a vida vivida de Ana emergem, hoje, pela voz - da Ana adulta, que se recorda e fala. Em sua voz, outras vozes apropriadas, seja pela cumplicidade ou alteridade, talvez de Olinda, de Regina ou de Rosa, ajudam a desmistificar mitos que se perpetuam socialmente disseminados.

Recebido em setembro de 2005 e aprovado em março de 2006.

\section{Notas}

1. Maurice Halbwachs desenvolve seus estudos partindo dos trabalhos de Émile Durkheim (1858-1917).

2. Para o desenvolvimento deste trabalho, buscamos o conhecimento de aspectos da história da educação especial do estado de Mato Grosso do Sul, na década de 1980, por ser o local 
e o período vividos pelo sujeito dessa história. Em nossas análises, buscamos entender a educação especial, deste determinado estado, entrelaçada ao movimento das idéias socialmente constituídas a respeito da deficiência e a aspectos da história da educação no Brasil. Posteriormente, localizamos pessoas que freqüentaram classes especiais para deficientes mentais no final da década de 1980, nas escolas públicas de uma cidade do interior dessa região. Realizamos entrevistas abertas com o intuito de reconstruir a história educacional desses sujeitos.

3. Esses depoimentos constituem material analisado em Kassar (1995). Na época, foram contatados todos os professores de "classe especial" que trabalhavam no município.

4. A "história oficial" foi retirada dos documentos sobre a vida escolar de Ana, arquivados na Unidade de Educação Especial do município pesquisado.

5. Excepcional era o termo utilizado nos documentos da época para designar a população atendida pela Educação Especial. Como exemplo, citamos a Lei 4.024/61.

6. Trata-se de um município do interior do estado de Mato Grosso do Sul.

7. Anteriormente à adoção dessa avaliação, havia uma média de 14 crianças por classe especial. Em 1988, ano do início da aplicação do diagnóstico, a média por classe caiu para 10 crianças, chegando, em 1990, a menos de 4 crianças por sala (cf. Kassar, 1995).

\section{Referências bibliográficas}

BAKHTIN, M. Estética da criação verbal. São Paulo: Martins Fontes, 1992.

BAKHTIN, M. Marxismo e filosofia da linguagem. São Paulo: HUCITEC, 1988.

BARTLETT, F.C. Remembering: a study in experimental and social psychology. Cambridge: Cambridge University, 1977.

BRAGA, E.S. O trabalho com a literatura: memória e histórias. Cadernos Cedes, Campinas, v. 20, n. 50, p. 84-102, abr. 2000.

BREJON, M. Estrutura e funcionamento do ensino de $1^{\circ}$ e $2^{\circ}$ graus: leituras. 20. ed. São Paulo: Pioneira, 1988.

BRASIL. Lei n. 5.692/71, 11 de agosto de 1971. Fixa Diretrizes e Bases para o ensino de $1^{\circ}$ e $2^{\circ}$ graus, e dá outras providências. Brasília, DF, Diário Oficial da Uniāo, 12/08/71.

BUENO, J.G. Educação especial brasileira: a integração/segregação do aluno deficiente. 1991. 214f. Tese (Doutorado em educação) Pontifícia Universidade Católica de São Paulo, São Paulo. 
Quando eu entrei na escola... memórias de passagens escolares

BUENO, J.G. A produção social da identidade do anormal. In: FreITAS, M.C. (Org.). História social da infância no Brasil. São Paulo: Cortez; USF, 1997.

CONTINI, M.L. Concepçôes de professores de $1^{a}$ série do $1^{\circ}$ grau do município de Corumbá-MS, sobre o processo de alfabetização. 1988. $170 \mathrm{f}$. Dissertação (Mestrado) - Programa de Estudos de Pós-Graduação em Psicologia da Educação, Pontifícia Universidade Católica de São Paulo, São Paulo.

FERREIRA, M.G. Psicologia educacional: análise crítica. São Paulo: Cortez; Campinas: Autores Associados, 1986.

GLAT, R. Somos iguais a você: depoimento de mulheres com deficiência mental. Rio de Janeiro: Agir, 1989.

GOFFMAN, E. Estigma: notas sobre a manipulação da identidade deteriorada. 3. ed. Rio de Janeiro: Zahar, 1980.

HALBWACHS, M. Memória coletiva. São Paulo: Vértice, 1990.

JANNUZZI, G. A educação do deficiente no Brasil: dos primórdios ao início do século XXI. Campinas: Autores Associados, $2004 a$.

JANNUZZI, G. Algumas concepções de educação do deficiente. Revista Brasileira de Ciências do Esporte, Porto Alegre, v. 25, n. 3, p. 9-25, maio 2004b.

KASSAR, M. Ciência e senso comum no cotidiano das classes especiais. Campinas: Papirus, 1995.

LURIA, A.R. Curso de psicologia geral I. Rio de Janeiro: Civilização Brasileira, 1979.

MARX, K. Contribuição à crítica da economia política. Trad. de Maria Helena B. Alves. 2. ed. São Paulo: Martins Fontes, 1983.

MARX, K.; ENGELS, F. A ideologia alemã. São Paulo: Moraes, 1984.

MAZZOTTA, M. Educação especial no Brasil: história e políticas públicas. São Paulo: Cortez, 1996.

MICHELET, A.; WOODILL, G. Le handicap dit mental: le fait social, le dagnostic, le traitement. Neuchâtel: Delachaux et Niestlé, 1993. 
OMOTE, S. A deficiência como fenômeno socialmente construido; palestra proferida na Faculdade de Educação, Filosofia, Ciências Sociais e da Documentação. Marília: UNESP, 1980.

PESSOTTI, I. Deficiência mental: da supervisão à ciência. São Paulo: T.A. Queiroz; EDUSP, 1984.

SCHAFF, A. O marxismo e o individuo. Rio de Janeiro: Civilização Brasileira, [s.d.].

SCHNEIDER, D. Alunos excepcionais: um estudo de caso de desvio. In: Velho, G. (Org.). Desvio e divergência: uma crítica da patologia social. Rio de Janeiro: Zahar, 1985.

SICA, C.M. Educação do deficiente mental. In: AssumpÇÃo JunIOR, F.B.; Sprovieri, M.H. (Org.). Introdução ao estudo da deficiência mental. São Paulo: Memnon, 1991.

SMOLKA, A.L.B. Esboço de uma perspectiva teórico-metodológica no estudo de processos de construção de conhecimento. In: GoÉs, M.C.R.; SmolKa, A.L.B. (Org.). A significação nos espaços educacionais: interação social e subjetivação. Campinas: Papirus, 1997.

SMOLKA, A.L.B.; GÓES, M.CR.; PINO, A. The construction of the subject: a persistent question. In: Wertsch, J.V. et al. Sociocultural studies of mind. Cambridge, Mass.: Cambridge University, 1995.

VYGOTSKY, L.S. Pensamento e linguagem. São Paulo: Martins Fontes, 1987.

VYGOTSKY, L.S. The genesis of higher mental functions. In: WERTSCH, J.V. (Ed.). The concept of activity in soviet psychology. New York: Sharpe, 1981. 